\title{
EL SUFIJO -ING EN ESPAÑOL Y CATALÁN: ANÁLISIS CONTRASTIVO DESDE LA PERSPECTIVA LEXICOGRÁFICA*
}

\author{
Marta Prat Sabater \\ Universitat Autònoma de Barcelona \\ marta.prat@uab.cat
}

Resumen: El objetivo de este artículo consiste en realizar un análisis contrastivo entre español y catalán sobre el uso del sufijo -ing de procedencia inglesa desde la perspectiva lexicográfica. En primer lugar, se compara la mayor o menor aceptabilidad de anglicismos con esta terminación en los diccionarios normativos y de uso de ambas lenguas románicas. En segundo lugar, se demuestra que, además de tratarse de un morfema derivativo que forma parte de importaciones léxicas, posee un valor productivo en la creación o aceptación de nuevas palabras con esta terminación. Por último, la valoración de su presencia en el contexto lexicográfico sugiere constatar en futuros trabajos la vitalidad de este sufijo en el uso espontáneo del español y el catalán.

Palabras clave: lexicología, lexicografía, derivación, anglicismos

\begin{abstract}
The objective of this article is to carry out a contrastive analysis between Spanish and Catalan on the use of the English suffix -ing from a lexicographical perspective. For this purpose, the greater or lesser acceptability of anglicisms is compared, first, with this word ending in the normative and use dictionaries of both Romance languages. Secondly, it is shown that, besides being a derivative morpheme which is part of lexical imports, it has a productive value in the creation or acceptance of new words with this ending. Finally, the assessment of its presence in the lexicographical context suggests that future researches will verify the vitality of this suffix in the spontaneous use of Spanish and Catalan.
\end{abstract}

Keywords: lexicology, lexicography, derivation, anglicisms

'La investigación de este trabajo ha sido posible gracias a la ayuda del Ministerio de Economía y Competitividad para los proyectos «El español de Cataluña en los medios de comunicación orales y escritos» (FFI2016-76118-P) e «Historia interna del Diccionario de la lengua castellana de la Real Academia Española en el siglo XIX (1869-1899)» (PGC2018-094768-B-I00), junto con el apoyo de la AGAUR de la Generalitat de Catalunya para el «Grup de Lexicografia i Diacronia» (2017 SGR 1251). 


\section{INTRODUCCIÓN}

La afirmación de que los cambios léxicos son los que se producen con mayor celeridad en cualquier lengua no sorprende ni a los estudiosos ni a los hablantes porque ambos pueden observarse de un modo sencillo en el transcurso de su existencia. En realidad, «es natural que así sea, puesto que el léxico es [...] el que más directamente refleja las realidades extralingüísticas» (Seco, 2007: 10). Estos fenómenos innovadores vinculados con la integración de nuevas palabras no solo se advierten a partir del análisis contrastivo y diacrónico de la historia de un determinado idioma, sino que pueden verse reflejados tanto en la cotidianidad como en ámbitos más especializados. Independientemente de cómo y dónde se localizan, no es posible prescindir de las variedades diatópicas y diastráticas, propias de todas las lenguas, ni de la perspectiva temporal, puesto que quien percibe posibles relevos léxicos debe establecer una comparación entre un antes y un ahora, del mismo modo que con el paso del tiempo debe saber identificar un después.

Desde el punto de vista histórico, resulta importante tener en cuenta que la ampliación de vocabulario está conectada con diversas características evolutivas, tanto internas (fonéticas, morfológicas y semánticas) como externas (desaparición de objetos, costumbres o palabras tabúes, entre otras), que pueden favorecer, aunque no de un modo exclusivo, la pérdida léxica (vid. Dworkin, 1989, 1998 y 2005; Cano, 1993; Álvarez de Miranda, 2009).

Desde la óptica sincrónica, diferentes factores inciden en la incorporación de neologismos de otras lenguas - en el presente, siguen prevaleciendo los anglicismos-. En el contexto sociolingüístico, el lenguaje de los jóvenes es, sin duda, el más receptivo y abierto a la modernidad que, desde la esfera léxica, puede interpretarse como responsable de innovaciones relacionadas con el inicio de posibles cambios lexicológicos ${ }^{1}$. En la vertiente informativa, los medios de comunicación poseen, asimismo, una función primordial en este sentido, puesto que, aparte de incluirse en ellos temáticas diversas, son representativos de las noticias más candentes de la actualidad. No resulta extraño, por lo tanto, leer que «el lenguaje de la prensa es uno de los fren-

\footnotetext{
${ }^{1}$ Resulta importante subrayar, aunque no sea objeto de estudio de este artículo, el enlace del mencionado grupo de usuarios de la lengua con las redes sociales (cfr. Vaqueiro Romero, 2012). Las estrategias discursivas utilizadas por estos internautas pueden influir en la innovación léxica. También se está ya trabajando con otras fuentes de información específicas como, por ejemplo, Twitter. García Rodríguez (2018) ha realizado una interesante investigación, integrada en un espacio geográfico bilingüe, acerca de las características lexicológicas del español de Cataluña extraídas de mensajes de la citada red social interactiva, cuyos resultados demuestran la influencia que ejerce, en este caso, el catalán sobre el español.
} 
tes más activos de la renovación del léxico» (Seco, 2007: 16), que no se corresponde exclusivamente con los significantes, sino también con su contenido semántico, tanto literal como expresado por medio de recursos cognitivos (en especial, la metáfora) o con eufemismos. Otra de las peculiaridades significativas se halla en el lenguaje especializado, ya que se constituye como una de las vías de entrada directa de nuevas voces que no siempre permanecen solo en el vocabulario científico, sino que también pueden extenderse a la lengua general (cfr. Santamaría Pérez, 2006; y, como ejemplo referido a un contexto más específico, Vila Rubio y Ciro, 2016).

Si desde el enfoque diacrónico se destaca la evolución como componente esencial del cambio léxico, desde el punto de vista sincrónico debe pensarse en el proceso de adaptación, que supone principalmente la acomodación (o no) de las nuevas palabras según las condiciones formales de la lengua receptora (cfr. Prat Sabater, 2016). En ambas perspectivas temporales, el tipo de alteración que pueda producirse está relacionado con diferentes niveles gramaticales, como el fonético y el morfológico, con la semántica y, de forma escrita, con la norma ortográfica.

Ante la innovación léxica, no puede omitirse la referencia a la lexicografía y a su complicidad en la aceptación de estas novedades. La tipología de los diccionarios (normativos o de uso) está vinculada con una mayor o menor predisposición a la admisión de nuevos lemas.

El contenido del presente artículo toma como punto de partida el inglés no solo para ratificar esta procedencia como una de las más influyentes en la aportación de nuevos vocablos a otros idiomas (en este caso, al español y al catalán), sino para demostrar su posible contribución en el ámbito de la morfología derivativa $(\$ 2)$. La incorporación de innovaciones léxicas con terminación -ing en los respectivos diccionarios normativos y de uso $(\$ 3)$ y el nivel de predisposición que muestra cada lengua en la adaptación formal, estructural y semántica del sufijo inglés indicado (\$ 4) permitirán reflexionar, desde el punto de vista lexicográfico, sobre el modo de integración de este tipo de voces en ambas lenguas.

\section{EL SUFIJO -ING: ¿MORFEMA DE IMPORTACIÓN O DE}

\section{CREACIÓN?}

Los procesos de creación neológica se relacionan con la formación de palabras mediante los recursos de la propia lengua, con la obtención de elementos léxicos de otros idiomas o con la adición de nuevos significados a voces existentes en el sistema lingüístico receptor (vid. Guerrero Ramos, 2013: 119). Sin embargo, en contadas ocasiones se pondera si la adquisición de un determinado afijo de procedencia ex- 
tranjera puede llegar a aceptarse y si tiene posibilidades de incorporarse al grupo de morfemas derivativos de que dispone el idioma que lo recibe. En caso de no admitirse como tal, conviene valorar si todo el vocablo consigue convertirse en préstamo léxico por cubrir una necesidad terminológica o si se mantiene como extranjerismo por su condición de novedoso o por el intento de desplazar posibles equivalencias de que ya dispone la lengua receptora.

\subsection{Anglicismos en -ing}

El uso del sufijo -ing en inglés constituye, ya de por sí, la suma de morfología flexiva y derivativa, según si se aplica a la formación del gerundio dentro del paradigma verbal o a su adjunción a una raíz o base derivativa de categoría gramatical distinta. Sea cual sea el proceso que se ejecute, los resultados obtenidos suelen ser nominalizaciones. Del mismo modo que dichas creaciones en -ing son muy comunes en inglés, tienden a transmitirse a muchas lenguas, entre ellas el español y catalán, en las que pueden actuar de modo independiente o con verbos de soporte (cfr. Romero Lesmes, 2015), entre otras posibilidades. Asimismo, resulta interesante considerar que este tipo de palabras no son exclusivas, por ejemplo, del lenguaje especializado, sino que se encuentran «tanto en registros coloquiales como formales» (Lorenzo García, 2007: 113).

$\mathrm{Al}$ igual que otras importaciones, en función de su grado de integración en la lengua receptora, pueden estar relacionadas tanto con la diacronía como con la sincronía. Por este motivo, desde el enfoque conceptual, reciben el nombre de préstamos léxicos aquellos que están completamente incorporados en la lengua de destino y extranjerismos los que son más recientes. En este segundo caso, se denominan peregrinismos cuando se trata de voces imprescindibles por el desconocimiento de lo que designan, o xenismos si son vocablos innecesarios o superfluos, puesto que la lengua que los adquiere ya posee otras equivalencias con el mismo significado (cfr. Prat Sabater, 2016). Aun así, si esto último sucede, a pesar de que existe un período de convivencia entre ambas opciones, lo más probable es que una de ellas desplace a la otra por razones de mayor frecuencia de uso.

De entrada, todas las unidades léxicas que presentan la terminación en -ing se consideran anglicismos. No obstante, en el proceso de transmisión léxica, es necesario tener en cuenta, según Pratt (1980), el étimo último (propio de la lengua de origen) y el étimo inmediato (directamente anterior a la lengua receptora). Aunque, a nuestro modo de ver, esta distinción no sea demasiado factible en este contexto que se estudia, en varias ocasiones se ha demostrado la posibilidad de que, si bien el punto de partida de esmoquin y pressing es la lengua inglesa, el francés puede haber actuado como intermediario (cfr., por ejemplo, Pratt, 1980; y Lorenzo, 1996). 
Estos mismos autores, entre otros, también hablan de falsos anglicismos y el ejemplo por excelencia es footing. Se trata de una «creación semántica seudoinglesa en francés para designar lo que ingleses y norteamericanos prefieren llamar jogging» (Lorenzo, 1996: 217). En esta ocasión, el galicismo es el que ha influido en mayor medida a otras lenguas. Desde nuestra perspectiva, lo que en realidad debe interpretarse es que, a pesar de que el sufijo -ing proceda del inglés, puede llegar a integrarse en otros idiomas. Lorenzo García ya empezó a advertir que «la formación de neologismos mediante el incremento de -ing se revela como un procedimiento productivo de creación y enriquecimiento léxicos en el ámbito de todas las lenguas románicas peninsulares» (2007: 115-116). Otros estudiosos, en el mismo año, pronosticaban lo mismo (Coll, 2007) e incluso esta idea se ha ido consolidando progresivamente. En la actualidad, ya podemos leer que «es curioso que un sufijo extranjero se haya abierto paso en la morfología castellana», lo que permite confirmar que «La adopción del sufijo -ing constituye una muestra más de la intensa anglización a que está sometido nuestro idioma» (Bustos, 2019).

\subsection{Formación de nuevas palabras en -ing o con sufijos equivalentes}

Las características de los afijos derivativos que posee una determinada lengua se indican, por lo general, en la gramática correspondiente cuando se analizan los recursos lingüísticos de que dispone para la formación de nuevas palabras. En otras ocasiones - aunque no siempre se adopta este criterio-, también se incluyen en diccionarios normativos e incluso de uso. Aun así, no resulta extraño que se prescinda de -ing en este tipo de obras, puesto que cualquier hablante, no necesariamente especialista en lingüística, tiende también a percibirlo como extranjerismo. Puede deducirse fácilmente, desde el punto de vista formal, que esta terminación no se caracteriza por respetar a final de palabra la combinación consonántica autóctona del español, según ya manifestó Seco en su DDDLE: «En algunas palabras de origen extranjero [el fonema $/ g /$ ] se presenta como sonido final —escrito g-: gong, Gog, Abisag, zigzag, iceberg, ring, swing, etc., así como la serie de términos ingleses en -ing derivados de verbos (living, camping, marketing, standing, etc.)» (s. v. $g$ ). A diferencia del español, la combinación consonántica -ng es habitual en catalán (fang, oblong, diftong...) del mismo modo que el equivalente ensordecido -nc (blanc, cinc, jonc...), equiparable este último a-enc/-enc(a), uno de los principales sufijos derivativos para la formación de adjetivos $(G L C, \S$ 10.2.2.). En oposición a lo que ocurre en español, -ing no es tan extraño para el catalán, circunstancia que podría llegar a explicar su aparente mayor cercanía al 
inglés y defender, además, los pocos cambios de adaptación que se producen en esta lengua, según se demostrará más adelante.

$\mathrm{Si}$ se desea conocer el origen de las terminaciones propias de cualquier lengua, se puede recurrir a diccionarios específicos de sufijos (como Pharies, 2002, para el español) o de formación de palabras (como López del Castillo, 2002, para el catalán), a gramáticas históricas (como Moll, 1991, para el catalán, y Penny 2006, para el español) o a monografías específicas (como Alvar y Pottier 1983, para el español). Sin embargo, solo una de estas obras indicadas incluye -ing como «sufix manllevat de l'anglès, que mostra una certa productivitat en la formació (adaptació) de neologismes (de diversos àmbits i també d'argot)» (López del Castillo, 2002: 250). Esto demuestra que a principios de este siglo una de las fuentes empieza a contemplar -ing como sufijo adoptado por el catalán que «forma noms (comunicació, economia, esports, publicitat)» (ibid.: 250). Dos años más tarde, ya se habla de la «naturalització del sufix -ing [...] per a la formació de mots» (Fargas y Paloma, 2004: 93) en el contexto de los medios de comunicación con la percepción de que «estem davant d'un camí només encetat, i que potser tindrà més endavant una importància creixent» (ibid.: 96).

En función de lo comentado hasta el momento, en la parte metodológica de presentación del corpus $(\$ 3)$ se constatará que este sufijo manifiesta implicaciones morfológicas para el español y el catalán que se concretarán en el apartado de análisis $(\$ 4)$. En atención a la morfología léxica, se tratará la importación de derivación y composición, ya producida en inglés; la adición, aunque simbólica en el ámbito lexicográfico, del sufijo -ing a raíces románicas; y la contraposición de incorporaciones en -ing con equivalencias en ambas lenguas receptoras, entre otras cuestiones.

\section{LEMAS ESPAÑOLES Y CATALANES EN -ING EN DICCIONARIOS NORMATIVOS Y DE USO}

El punto de partida para la obtención de datos objeto de análisis está constituido por varios repertorios lexicográficos. En este contexto metodológico, se han escogido para esta investigación dos tipos de obras, según lo que ya dejó establecido en su momento Martínez de Sousa (1995). Por un lado, las conocidas como diccionarios normativos, cuyos representantes, en este caso, son las últimas ediciones de la Real Academia Española y la Asociación de Academias de la Lengua Española (Diccionario de la lengua española) y del Institut d'Estudis Catalans (Diccionari de la llengua catalana), ambas en proceso de actualización en línea hasta que se publique la siguiente edición. Por otro lado, los diccionarios de uso, representados, para las respectivas lenguas, por la reconocida editorial SM (Diccionario de uso del español 
actual) y por el propio Institut d'Estudis Catalans (Diccionari descriptiu de la llengua catalana), ambos disponibles también en línea. En las obras lexicográficas indicadas se han encontrado todos los lemas considerados como anglicismos directos o indirectos, principalmente por su terminación en -ing con o sin adaptación, según se demostrará en este artículoº .

\subsection{Diccionarios normativos: DLE y DIEC2}

El concepto de diccionario normativo se interpreta desde el punto de vista tradicional como reflejo de un modelo de lengua representativo de los preceptos léxicos, habitualmente defendidos por la correspondiente institución académica. Esta es la razón principal por la que se justifica la reticencia respecto a la inclusión de neologismos, sobre todo si poseen la característica de extranjerismo, u otro tipo de palabras que forman parte de la variedad diatópica o de diferentes registros relacionados con cuestiones diastráticas (argots) o diatécnicas (jergas). No obstante, según demostraron Haensch y Omeñaca (2004: 62), el avance del desarrollo lexicográfico contribuye a la aproximación de este tipo de obras con las de carácter descriptivo, que se tratarán en el siguiente apartado. Dicho de otro modo, adquieren progresivamente un «carácter mixto normativo-descriptivo» por ir destinadas a «un público muy amplio» (Haensch y Omeñana, 2004: 207).

Desde esta perspectiva, no resulta extraño localizar en el Diccionario de la lengua española (DLE) y en el Diccionari de la llengua catalana (DIEC2) determinadas voces con características propias de lenguas ajenas, puesto que presentan condiciones que descartan no solo los preceptos ortográficos, sino incluso morfológicos de la lengua receptora. A pesar de ello, por lo general, se trata de peregrinismos, en el sentido de importaciones léxicas imprescindibles que no suelen disponer de equivalencias autóctonas que permitan sustituirlas (cfr. Prat Sabater, 2016: 261). Quizá este es uno de los principales motivos de admisión de dichas palabras en este tipo de obras.

En cuanto a valoración cuantitativa, es significativo destacar que ambas obras lexicográficas poseen un número muy similar de lemas terminados en -ing (24, el $D L E ; 22$, el DIEC2). Resulta aún más significativo que 15 de ellos aparecen integrados en ambos diccionarios junto con otro equiparable en las dos lenguas, pero con diferencias: en catalán se mantiene la terminación inglesa (zàping), mientras que en español solo se acepta su adaptación con sufijo propio (zapeoo). Por lo que atañe al resto de ejemplos, 8 son exclusivos para el español desde el enfoque lexicográfico

${ }^{2}$ Vid. el Anexo para la consulta de este tipo de lemas y correspondientes variantes y/o equivalencias, resultado del exhaustivo vaciado de los diccionarios mencionados. 
(catering, jogging, living, overbooking, puenting, sparring, standing, windsurfing) y 6 para el catalán (caravàning, dàncing, fàding, antifàding, fouling, pircing). Cabe destacar que, aunque antidumping solo esté registrado en el $D L E$, en la obra catalana se integra también dúmping y anti-como lemas, por lo que se da por sentado que, si se acepta el primero, es posible deducir la existencia de la correspondiente oposición después del proceso de formación de palabras. Aun así, quizá la no inclusión tiene otra razón de base. Si el diccionario catalán incluye fàding y antifáding como entradas, es probable que la poca frecuencia de uso de antidúmping impida su consideración como lema aparte ${ }^{3}$.

\subsection{Diccionarios de uso: $C L A V E$ y $D D L C$}

Los diccionarios de uso se interpretan básicamente como descriptivos, puesto que, según ya indicó Martínez de Sousa (1995), se trata de una «forma moderna de diseño», cuya función es la de «recoger y definir adecuadamente el lenguaje hablado y escrito de una comunidad en un momento determinado (sincronía), sin criterios puristas ni normativos» (s. v. diccionario de uso). Se caracterizan, de un modo específico, por tres tipos de ampliaciones: paradigmática (adición de sinónimos, antónimos y/o equivalencias léxicas), sintagmática (uso contextual desde el punto de vista morfosintáctico) y mediante frases-ejemplo (cfr. Haensch y Omeñana, 2014).

Para esta investigación se ha decidido escoger el Diccionario de uso del español actual (CLAVE) y el Diccionari descriptiu de la llengua catalana $(D D L C)$, aunque existe entre ellos una diferencia cuantitativa muy importante relativa al tipo de palabras estudiadas en este artículo. Ambas obras cumplen el criterio expuesto en el párrafo anterior; sin embargo, mientras que la editorial SM manifiesta una tradición significativa en la elaboración de diccionarios de uso, esta tarea no es tan destacable en el $D D L C$. Aun así, en la presentación en línea de este diccionario, se especifica que «és un projecte lexicogràfic de gran abast que es desenvolupà a l'IEC entre 1998 i 2016» y que «pren com a referència descriptiva exclusiva els materials lèxics reu-

${ }^{3}$ Por motivos de espacio, no se puede proceder a la consulta de corpus de ambas lenguas, salvo en esta nota en la que se hace una excepción. La BOBNEO ofrece 28 resultados de dúmping y 13 de antidúmping para el catalán, mientras que sobre fáding, solo facilita 1 y ninguno de antifáding. Estos datos, de entrada, contradicen la decisión adoptada por el DIEC2. En cuanto a las opciones españolas, en la $B O B N E O$ se hallan 8 ejemplos de dumping y 24 de antidumping, lo que confirma la decisión del DLE. El CORPES XXI registra muchos más casos de dumping/antidumping para el español y solo 2 de fading, uno en territorio peninsular y otro en Argentina. Estas ocurrencias, por el momento, siguen corroborando la decisión del $D L E$. No obstante, en investigaciones posteriores deseamos profundizar acerca de la frecuencia de uso de nuevas voces de este tipo para corroborar su necesidad de integración (o no) en obras lexicográficas. 
nits en el Corpus Textual Informatitzat de la Llengua Catalana (CTILC), que té un abast temporal de 1833 a 1988» junto con «informacions procedents d'una base de dades lexicogràfica (BDLex) formada per 13 diccionaris catalans». A pesar de que no puede obviarse una menor actualización cronológica que la producida en el $C L A V E$, es importante destacar que, en cuanto a la temática investigada, no se observa, como suele ocurrir en los diccionarios normativos, el predominio de peregrinismos en lo que recoge al menos la obra de uso española. Sin embargo, también se advierte, según se demostrará más adelante, la inclusión de xenismos, es decir, de extranjerismos superfluos por disponer, según las indicadas referencias lexicográficas, de equivalencias en las respectivas lenguas que podrían emplearse en su lugar (cfr. Prat Sabater, 2016: 261).

Tal y como se ha comentado en las líneas precedentes, a diferencia de la equiparación cuantitativa del $D L E$ y del $D I E C 2$, la cantidad de extranjerismos en -ing del $C L A V E$ asciende a 118, mientras que la del $D D L C$ no llega a una tercera parte (36). Esta desproporción numérica podría quedar justificada por las distinciones de actualización temporal de ambas obras o, desde otra óptica, por las diferencias de aceptación de este tipo de palabras por los hablantes de ambas lenguas.

Del total de palabras recogidas, 25 están registradas en ambos diccionarios. Por lo que atañe al resto de ejemplos, 11 son exclusivos del $D D L C$ para el catalán (action-painting, darling, dry-farming, fàding, iòting, quisling, shocking, skating, sleeping, zóning y plum-puding, a pesar de que ambas lenguas comparten, con las correspondientes variantes, la misma base derivativa: púding, en catalán, o pudin, en español) y 93 del CLAVE (bartering, climbing, editing, feeling, goming, karting, looping, outing, peeling, renting, shopping, timing, vending, wrestling, yearling, etc. $)^{4}$.

\subsection{Coincidencia de datos entre diccionarios normativos y de uso}

Después de relatar la distribución de los datos obtenidos en función de la tipología de obras de las que forman parte, resulta interesante contrastar qué se encuentra en el conjunto de todas ellas o, como mínimo, en dos o tres. Las distinciones principales de estos repertorios, según se ha indicado, son, por un lado, la lengua y, por otro, el criterio lexicográfico seguido para su elaboración.

Si se toma como punto de partida la cantidad de extranjerismos hallada en los diccionarios normativos, más de la mitad (en concreto, 13) aparecen en las cuatro obras, lo que demuestra un alto grado de integración desde los dos enfoques lexicográficos. Interesa subrayar que no todos pertenecen al mismo campo semántico,

${ }^{4}$ Para la consulta de todos los ejemplos, vid. Anexo. 
sino que se observa variedad al respecto. Aparte de voces más generales como parking (esp.) / párquing (cat.) o de términos relacionados con distintas áreas como ranking, ranquin (esp.) / ránquing (cat.), se observa la siguiente distribución por campos semánticos:

(1) economía: dumping (esp.) / dúmping (cat.); holding (esp.) / hòlding (cat.); leasing (esp.) / lising (cat.); marketing, márquetin (esp.) / màrqueting, marquèting (cat.);

(2) cinematografía, música y/o TV: casting, castin (esp.) / cásting (cat.); trávelin, travelling (esp.) / tráveling (cat.);

(3) turismo: camping, campin (esp.) / cámping (cat.);

(4) ropa: esmoquin, smoking (esp.) / esmóquing (cat.);

(5) deporte:footing (esp.) / fúting (cat.);

(6) política: mitin, mitin, meeting (esp.) / miting, mitin, mitin (cat.);

(7) postre:pudin, pudin, budin (esp.) / púding, budin (cat.).

Según se ha indicado con anterioridad, puede ocurrir que otros ejemplos concretos (en total, 7) predominen bien en diccionarios normativos, bien en diccionarios de uso, o que solo se equiparen en uno de cada tipo, pero de lengua distinta:

(1) DLE, DIEC2; CLAVE: lifting (esp.) / lifting (cat.); rafting (esp.) / räfting (cat.);

(2) DLE; CLAVE, DDLC: living (esp.) / living (cat.); standing (esp.) / estànding (cat.);

(3) DIEC2; CLAVE, DDLC: caravaning (esp.) / caravaning (cat.); dancing (esp.) I dáncing (cat.);

(4) DIEC2; CLAVE: pirsin, piercing (esp.) $)^{5} /$ pircing (cat.).

Los datos numéricos han predominado tanto en los $\$ \$ 3.1$ y 3.2. como en este. En todos ellos, en especial en el $\$ 3.3$., se advierten algunas diferencias en la estructura formal de dichos términos de acuerdo con la lengua de la que forman parte o con las variantes que se encuentran, sobre todo, en español. Estas diferencias se constituyen como el preámbulo de lo que se profundizará, junto con otros ítems, en el siguiente apartado.

${ }^{5}$ Sorprende que en el $D P D$ se incluya pirsin (y piercing), aunque se prefiera perforación (corporal) o perforado, y que en el $D L E$ no se registre el anglicismo, que suele ser bastante habitual. Para más información al respecto, vid. Prat Sabater y Sierra Infante (2011: 154-155). 


\section{ANÁLISIS CONTRASTIVO DE LA INCORPORACIÓN DE ANGLICISMOS EN -ING EN LAS LENGUAS ESPAÑOLA Y CATALANA DESDE LA PERSPECTIVA LEXICOGRÁFICA}

El corpus elaborado para esta investigación permite un análisis minucioso desde tres puntos de vista distintos: ortográfico $(\$ 4.1$.), morfológico ( $\$ 4.2$.) y semántico ( $\$$ 4.3.). La base de este proceso reside fundamentalmente en el contraste entre español y catalán, además de la valorar cómo actúa cada una de estas lenguas, desde la perspectiva lexicográfica, en estas tres vertientes lingüísticas.

\subsection{Adaptación ortográfica}

A lo largo del presente trabajo se ha realizado la distinción entre dos aspectos fundamentales para el contexto lexicológico (diacrónico y sincrónico), directamente relacionados con el grado de aceptación de las correspondientes voces en la lengua receptora y la posibilidad o imposibilidad de deducción por parte de los hablantes de si se trata o no de importaciones foráneas.

Se han hallado algunos ejemplos que rozan la concepción de préstamo léxico, si no se interpretan ya como tales, puesto que en español se presentan formalmente adaptados en el ámbito lexicográfico: esmoquin, mitin, pudin o trávelin ${ }^{6}$. En realidad, la Ortografía de la lengua española (2010) indica que «Los préstamos del inglés que en esa lengua presentan la terminación -ing se han adaptado tradicionalmente al español eliminando la - $g$ final, de acuerdo con la pronunciación espontánea de los hispanohablantes, que en general no articulan la última consonante». Del mismo modo, «recomienda seguir acomodando a esta pauta tradicional los numerosos anglicismos que circulan hoy con esa misma configuración, si se decide adaptarlos al español». Especifica, además, las causas principales como «su falta de equivalentes en la propia lengua»o «su arraigo y generalización en el uso actual» (\$ 6.2.2.2.1.). Aun así, en la última edición del $D L E$, por ejemplo, todavía no predomina esta recomendación.

El catalán, en cambio, no modifica el sufijo inglés, sino que aplica su propio criterio de acentuación: esmóquing, míting, púding, tràveling. El motivo principal reside en que la terminación -(i)ng no es tan extraña para esta lengua, según se ha determinado con anterioridad (vid. $\$ 2.2$. de este artículo).

${ }^{6}$ En el $D P D$, las correspondientes unidades inglesas remitían a estas opciones adaptadas, que son las únicas que aparecen en la última edición del $D L E$, lo que demuestra la evolución lexicográfica que se ha producido para aquellas voces que ya se consideran propias del español, aunque no siempre se tengan en cuenta las preferencias de los usuarios desde el punto de vista gráfico. 
Aparte de estas precisiones previas, es evidente, sin embargo, que ambas lenguas han realizado los oportunos cambios vocálicos o consonánticos en los ejemplos indicados, directamente relacionados con la pronunciación: adición de $e$ - protética a la $s$-inicial (ing. smoking), cambio de -e-geminada por - $i$ - (ing. meeting) o degeminación de -dd- (ing. pudding) o de -ll- (ing. travelling).

En español, solo se halla la aceptación de smoking y travelling en el CLAVE, aunque el primero de ellos llegó a formar parte de dos ediciones del Diccionario manual e ilustrado de la lengua española (1927 y 1950) ${ }^{7}$, pero las dos voces inglesas nunca se integraron en ningún diccionario académico usual. Para este tipo de obras, la primera documentación se produce en el DRAE 1970 (19. ${ }^{a}$ ed.), con las siguientes formas ya adaptadas: esmoquin y trávelin (sobre la primera de estas palabras, cfr. Prat Sabater, 2016: 283-284).

Ambas lenguas comparten variantes del étimo inglés meeting: mitin (DLE, $C L A V E$ y $D D L C)$ y mitin, opción preferente para el español general (DLE y CLA$V E)$ y aceptada en catalán en el $D D L C$. El CLAVE es el único que sigue registrando la forma original meeting. La primera documentación de mitin ya figura en el $D R A E$ 1914 (14.a ed.) — de ahí su condición más diacrónica que sincrónica- y la de mitín aparece por primera vez en el $D L E$.

El étimo pudding manifiesta, asimismo, variantes formales tanto en español como en catalán: pudin y budin (DLE y CLAVE) y budin $(D D L C)$. Desde la perspectiva de la RAE, budín es la primera documentación lexicográfica de esta palabra en el DRAE 1925 (15. ed.). Pudin aparece por primera vez en el Diccionario manual e ilustrado de la lengua española (1927) y pudín en el DRAE 1970 (19. a ed.). Ambos remiten a budin. La forma pudin no se considera preferente hasta la 22.a ed. (2001).

En el contexto de extranjerismos, interpretables estos últimos como palabras de incorporación más reciente tanto en español como en catalán, debemos ubicar los peregrinismos que, como se ha indicado con anterioridad, desde el enfoque lexicográfico no poseen correspondencias léxicas en ninguna de las dos lenguas. Es lógico, por tanto, que la mayoría se consideren aún como anglicismos por parte de los hablantes y que el grado de adaptación gráfica sea inferior, sobre todo para el español.

En las cuatro obras consultadas solo se encuentra dumping (esp.) / dúmping (cat.); en los dos diccionarios normativos y en el CLAVE, rafting (esp.) / räfting (cat.); en los dos diccionarios de uso y en el DIEC2, caravaning (esp.) / caravàning (cat.); en las dos obras españolas y con distinción de variantes, catering $(D L E)$ / cáterin y cate-

${ }^{7}$ Para la consulta de ediciones de diccionarios académicos anteriores al $D L E$, se utiliza el NTLLE. 
ring $(C L A V E)$, sparring $(D L E)$ / esparrin y sparring $(C L A V E)^{8}$, windsurfing / wind surfing $(D L E$ y $C L A V E)$; en los dos diccionarios catalanes, fading ( $D L E$ y $D D L C)$; en las dos obras de uso, con o sin distinción de variantes, cracking, happening (CLAVE y $D D L C)$, building (CLAVE), building / uilding (DDLC),planning (CLAVE), plàning $(D D L C)$; en el diccionario normativo catalán, fouling, iòting (DIEC2); en el diccionario de uso catalán, darling, dry-farming, quisling, shocking, skating, sleeping y zòning $(D D L C)$. El número más representativo de peregrinismos, con o sin variantes gráficas, se localiza en el CLAVE (branding, cycling, filling, grooming, packaging, phishing, roaming, spamming, spinning, streaking / estriquin, trading, walking, yachting, etc.) ${ }^{9}$.

\subsection{Implicación morfológica}

A pesar de que en este apartado se vaya a conceder mayor importancia a la morfología léxica, no podemos proceder a su análisis sin un breve comentario sobre la morfología flexiva, incluida de los diccionarios de uso, tanto en español (CLA$V E)$ como en catalán $(D D L E)$. Al tratarse de un corpus formado esencialmente por sustantivos, es lógico que tienda a proponerse la pluralización tanto para voces adaptadas como para las que conservan la terminación -ing: campings, cámpines (esp.) / cámpings (cat.); holdings (esp.) / hòldings (cat.); rankings, ránquines (esp.) / ränquings (cat.); etc.

Desde el punto de vista de la morfología léxica, es esencial distinguir entre diversas vertientes de formación de palabras que, por un lado, pueden haber ocurrido en el propio inglés y, por otro, pueden haberse llevado a cabo desde diferentes enfoques en las lenguas receptoras, principalmente en español. A continuación, se presentan ejemplos de cada tipo, cuya información completa puede consultarse en los datos incluidos en el Anexo:

(1) Transmisión de extranjerismo en -ing y correspondiente derivado creado de la lengua inglesa: doping y antidoping, dumping y antidumping (esp.); fáding y antifáding (cat.), púding y plum-púding (cat.).

(2) Transmisión de compuestos léxicos o sintagmáticos formados en la lengua inglesa. Podemos localizar ejemplos sin variante (brainstorming, kick boxing, e-lear-

\footnotetext{
${ }^{8}$ Cuando la opción preferente del diccionario de uso es la adaptada y esta no figura en el normativo, es posible que haya quedado obsoleta, puesto que el $D L E$ es de actualización más reciente. El CORPES XXI lo confirma, ya que esparrin aparece solo en 1 caso en el español peninsular (2008), mientras que sparring, en 116 casos distribuidos entre 78 documentos, tanto pertenecientes al área peninsular como hispanoamericana (2001-2016).

$9 \quad$ Para más datos al respecto, vid. Anexo.
} 
ning $^{10}$ (esp.); action-painting, dry-farming (cat.)); con variante (aquaplaning / acuaplaning (esp.)); o con variación en una sola parte de la composición (bodybuilding, body painting (esp.)).

(3) Traducción de la raíz y cambio de sufijo -ing por otro de la lengua receptora semánticamente equiparable. Se trata de equivalencias (sobre todo del español) para extranjerismos aceptados: piercing $\rightarrow$ perforación, missing $\rightarrow$ desaparecido, leasing $\rightarrow$ arrendamiento con opción de compra (esp.) / lising $\rightarrow$ arrendament financer (cat.); sampling $\rightarrow$ muestreo, etc. Relacionado con este último ejemplo, existe una sola opción en la que se mantiene la raíz inglesa, además de ser la única que acepta el DLE (zapeo), a diferencia del CLAVE (zapping $\rightarrow$ zapeo $)$.

(4) Adición del sufijo -ing a una raíz española: puenting y balconing. A pesar de que que tanto el CLAVE como el DPD propongan puentismo como equivalencia para esta última palabra, el $D L E$ ya no lo contempla. En cuanto a balconing, que es más reciente, Reverte (2010: 44) ya especificó que los medios de comunicación fueron los que le concedieron esta denominación a la acción de «tirarse desde un balcón de un hotel a una piscina, a ser posible desde una altura de cinco, seis o siete pisos». De un modo irónico, aunque realista, evidenció que la mayoría que lo practicaron «ganaron el féretro a pulso».

(5) Creación de otras voces o expresiones con posibles diferencias semánticas a partir del extranjerismo incorporado en español y catalán, esté o no adaptado ${ }^{11}$ : surfista (DLE, CLAVE y DIEC2); dar el mitin ${ }^{12}$ (CLAVE), mitinguer, mitinguesc, miting de protesta, $\sim$ de propaganda, $\sim$ politic, $\sim$ electoral, celebrar un $\sim$, organit-

${ }^{10}$ Este extranjerismo solo se propone en el CLAVE (s. v. e-learning); sin embargo, en el DPD (s. v. electrónico, -ca), se especifica que la «e- antepuesta, [se considera una] abreviación extrema del adjetivo inglés electronic» y se muestra favorable a «desterrar numerosos anglicismos» de este tipo. Quizá esta sea una de las causas principales por la que e-learning no esté registrado en el $D L E$, puesto que, en su lugar, muy probablemente ya se utilice aprendizaje por internet, equivalencia propuesta por el CLAVE.

${ }^{11}$ En este caso, el concepto expresión no puede particularizarse porque se trata de derivados, compuestos sintagmáticos, colocaciones o locuciones, según queda indicado en la fuente a la que pertenecen, aunque la elección escogida por una obra no siempre coincide con la que propone el resto. Resulta esencial indicar que no todos los estudiosos están de acuerdo con el proceso de interpretación de estos tres últimos términos. Pensamos que la distinción que ofrece el $D D L C$ sobre colocación (tràveling lateral) y locución nominal (tràveling òptic), aparte de otros ejemplos de este tipo que proporciona, no es correcta, puesto que ambos son compuestos sintagmáticos. Para una explicación conceptual completa de las unidades fraseológicas del español y del catalán, desde las perspectivas cognitivista y contrastiva, en oposición a compuesto sintagmático, vid. García Rodríguez (2019), capítulo 1 y, de un modo más concreto, $\$ 6.2 .2 .5$.

${ }^{12}$ Para un recorrido histórico de mitin y la aparición de esta locución con un matiz semántico distinto, vid. Zamora Vicente (1986). 
zar un $\sim$, donar un $\sim(D D L C)$; camping gas (CLAVE), material de càmping, terrenys de $\sim$, practicar el $\sim$, fer $\sim(D D L C)$; budin azteca $(D L E)$, púding de fruites, $\sim$ de panses, $\sim$ de gelat $(D D L C)$; dúmping social (DIEC2 y DDLC); entre otros.

\subsection{Correlación y variación semántica}

Los xenismos, según se ha comentado, muestran relación directa con las equivalencias propuestas para ambas lenguas, que podrían llegar a interpretarse como correlaciones semánticas. En este punto se encuentra el debate de si los usuarios están más o menos de acuerdo con las decisiones lexicográficas. Al no poder tratar, por razones de espacio, dicha cuestión en este trabajo, aceptamos como válidas las resoluciones institucionales que se presentan a continuación, aunque somos conscientes de que en ocasiones podrían oponerse a las tendencias sincrónicas del momento.

Es esencial destacar que no todos los extranjerismos se sustituyen por una voz independiente, sino que pueden optar, según se observa en el Anexo, por expresiones formadas por dos o más palabras: dripping $\rightarrow$ pintura de goteo, hadling $\rightarrow$ servicios de asistencia, o mailing $\rightarrow$ envio postal ${ }^{13}$. Sobre este último ejemplo del CLAVE (s. v. mailing), podría precisarse que la interpretación semántica puede ser relativa, puesto que el adjetivo postal presenta una vinculación más directa con el servicio tradicional de correos que con la distribución por internet (cfr. DLE, s. v. postal).

También puede ocurrir que la sustitución propuesta sea múltiple, es decir, que se ofrezca una sola palabra (o más de una) junto con una expresión: briefing $\rightarrow$ informe, reunión informativa; ranking $\rightarrow$ lista, tabla clasificatoria, clasificación, escalafón.

Los casos mencionados con anterioridad en los que la equivalencia es una única voz (o más de una del mismo tipo) no son precisamente los que prevalecen: casting / castin $\rightarrow$ audición; overbooking $\rightarrow$ sobreventa, sobrecontratación, sobreocupación; parking $\rightarrow$ aparcamiento (esp.) / pàrquing $\rightarrow$ aparcament (cat.); legging $\rightarrow$ malla. Desde el punto de vista semántico, a nuestro modo de ver, la equivalencia que se propone para este último ejemplo no es idónea porque su significado ('Prenda de vestir, generalmente deportiva, elástica y fina, que se ajusta mucho al cuerpo', $C L A V E$, s. v. malla) no es idéntico al del anglicismo ('Prenda de vestir que consiste en una malla ceñida al cuerpo desde la cintura a los tobillos', CLAVE, s. v. legging).

Aparte de lo que acaba de comentarse, consideramos oportuno destacar infor-

${ }^{13}$ Estas evidencias pueden relacionarse con una de las vertientes del principio de economía lingüística, lo que permite justificar por qué, en determinadas ocasiones, los usuarios prefieren los anglicismos en -ing, antes que el uso de expresiones autóctonas más complejas. Para información más detallada al respecto, cfr. Paredes Duarte (2007-2008). 
mación adicional al respecto relativa al $D L E$, que incluimos en el Anexo. En ocasiones, solo se indican equivalencias, la mayoría correspondientes a las que ofrece el $C L A V E$. La divergencia principal de ambas obras estriba en que el diccionario académico no ofrece la alternativa inglesa, probablemente por razones de preferencia exclusiva por la opción española: uso de acoso laboral en lugar de bossing, de acoso escolar en lugar de bullying, de dopaje en lugar de doping, etc. En el DIEC2, ocurre lo mismo en este último caso (dopatge) y en sala d'estar en lugar de living (DDLC).

A diferencia del CLAVE, que proporciona (aunque no siempre) la remisión a una forma española en su totalidad, es decir, sin precisar el sentido específico al que se refiere el extranjerismo, para el $D L E$, en el Anexo, solo se ha optado por indicar la acepción de la equivalencia aplicable al contexto semántico del que forma parte la opción en -ing, que es el único válido: bolera ${ }^{I}$ 'Lugar destinado al juego de bolos' en lugar de bowling (ocio), regate 'En fútbol y otros deportes, finta que hace un jugador para sortear a uno o varios contrarios y no dejarse arrebatar el balón' o finta 'En algunos deportes de competición, movimiento inesperado que se hace para sortear al contrario' en vez de dribbling o dríbling (deportes), en español y catalán respectivamente, etc.

Ya para cerrar este último apartado, resulta importante distinguir el número de equivalencias que incluyen los diferentes diccionarios. Si se tienen en cuenta los datos numéricos proporcionados en el $\S 3$, es esperable observar que ambas obras catalanas las facilitan en menos ocasiones ( 3 en el $D I E C 2$ y 5 en el $D D L C$ ) y las españolas, como es lógico, en un número mayor (11 en el $D L E$ y 45 en el $C L A V E)$.

\section{CONCLUSIÓN}

Los repertorios lexicográficos resultan esenciales para advertir que los anglicismos en -ing se han incorporado en las lenguas estudiadas, sobre todo en español si se tiene en cuenta el diccionario de uso seleccionado. Se ha podido observar que, en función del tiempo transcurrido, están más o menos aceptados en las obras normativas, lo que favorece el proceso de adaptación gráfica, especialmente en catalán por poseer el mismo tipo de combinación consonántica a final de palabra. Desde el punto de vista semántico, es conveniente destacar la pugna entre los extranjerismos en -ing y las equivalencias que ya se encuentran en español y catalán, cuyas preferencias tienden a deducirse por la frecuencia de uso por parte de los hablantes. Lo más significativo, sin embargo, se halla en las implicaciones morfológicas que se observan en la aceptación de importaciones con esta terminación. En catalán, ya se ha demostrado que -ing empezó a incluirse como sufijo para la formación de nuevas palabras desde principios de este siglo. En español, de momento, se acepta lexico- 
gráficamente como integrante de nuevas unidades léxicas. Este efecto predispone a estudiar si en contextos más espontáneos se incrementa su empleo para la creación de nuevas voces con raíz española y si, con su función derivativa recurrente, se puede llegar a desestimar la concepción de falso anglicismo.

El análisis del sufijo -ing en el uso coloquial y la consulta de corpus orales y escritos que permitan verificarlo son recursos esenciales que podrían llegar a evidenciar si, tanto para el español como para el catalán, este morfema se considera no solo productivo, sino un componente más de la morfología léxica.

\section{BIBLIOGRAFÍA}

Alvar, Manuel y Bernard PotTier (1983): Morfología histórica del español, Madrid, Gredos.

Álvarez de Miranda, Pedro (2009): «Neología y pérdida léxica », en Elena de Miguel (ed.), Panorama de la lexicología, Barcelona, Ariel, pp. 133-158.

$B O B N E O=$ Base de datos de neologismos de los medios de comunicación (catalán-español), Barcelona, Universitat Pompeu Fabra, Observatori de Neologia. En línea: <http://obneo.iula.upf.edu/bobneo/index.php> [julio 2019].

Bustos, Alberto (2019): «El sufijo -ing», Blog de Lengua. En línea: <https:// blog.lengua-e.com/2019/el-sufijo-ing/> [octubre 2019].

Cano, Rafael (1993): «La muerte de las palabras», en Esperanza R. Alcaide, Francisco J. Salguero y María del Mar Ramos (coords.), Estudios lingüísticos en torno a la palabra, Sevilla, Universidad de Sevilla, Facultad de Filología, pp. 41-57.

$C L A V E=$ Maldonado González, Concepción (dir.) (2012): CLAVE. Diccionario de uso del español actual, Madrid, Ediciones SM. En línea: <http://clave. smdiccionarios.com> [mayo 2019].

Coll, Alba (2007): «El sufijo -ing, ¿creatividad al poder?», Donde dice... (Boletín de la Fundéu), 9, p. 16.

CORPES XXI = REAL ACADEMIa EsPaÑola y Asociación DE ACADEMIAS de LA Lengua Española: Corpus del español del siglo XXI. En línea: <http:// www.rae.es/recursos/banco-de-datos/corpes-xxi> [julio 2019].

DDDLE = SECo, Manuel (2005): Diccionario de dudas y dificultades de la lengua española, 10. ${ }^{\text {a }}$ ed., Madrid, Espasa Calpe.

DDLC = Institut D'Estudis Catalans (1998-2016): Diccionari descriptiu de la llengua catalana. En línea: <http://dcc.iec.cat/ddlci/scripts/index.html> [mayo 2019] 
DIEC2 = Institut D'Estudis Catalans (2019[2007]): Diccionari de la llengua catalana, $2 .^{\mathrm{a}} \mathrm{ed}$. actualizada en línea. En línea: <http://dlc.iec.cat > [mayo 2019].

DLE $=$ Real ACAdemia Española y Asociación de Academias de la Lengua Española (2018[2014]): Diccionario de la lengua española, 23. ${ }^{\mathrm{a}} \mathrm{ed}$. actualizada en versión electrónica 23.2. En línea: <https://dle.rae.es> [mayo 2019].

$D P D=$ Real Academia Española y Asociación de Academias de la Lengua Española (2005): Diccionario panhispánico de dudas. En línea: <https://www.rae.es/recursos/diccionarios/dpd> [junio 2019].

Dworkin, Steven (1989): «Factores lingüísticos operantes en la pérdida léxica», en Actes du XVIII Congrès International de Linguistique et de Philologie Romanes, Tubinga, Max Niemeyer Verlag, 4, pp. 379-384.

Dworkin, Steven (1998): «Yakov Malkiel's Contributions to the Study of Lexical Loss: A Critical Overview», Romanistik in Geschichte und Gegenwart, 5, pp. 3-19.

Dworkin, Steven (2005): «La Historia de la Lengua y el cambio léxico», Iberoromania, 62, pp. 59-70.

FARgas, F. Xavier y David Paloma (2004): «Els mitjans de comunicació en català i la naturalització del sufix -ing en la formació de mots », Els Marges, 75, pp. 87-98.

GARcía Rodríguez, Joseph (2018): «La presencia de fenómenos del contacto de lenguas en Twitter: el caso del español de Cataluña », ELUA, 32, pp. 131-154. En línea: <http://dx.doi.org/10.14198/ELUA2018.32.6>.

García Rodríguez, Joseph (2019): Las unidades fraseológicas del español y el catalán con elementos de la naturaleza: estudio cognitivo-contrastivo y propuesta de un diccionario electrónico de fraseología bilingüe. Tesis doctoral publicada en línea: <https://www.educacion.gob.es/teseo/mostrarRef. do?ref $=1259292 \#$ >.

GLC = Institut D'Estudis CATALANs (2016): Gramática de la llengua catalana, Barcelona, IEC.

Guerrero Ramos, Gloria (2013): «El préstamo lingüístico, uno de los principales procedimientos de creación neológica », Quaderns de Filologia: Estudis Lingüistics, XVIII, pp. 115-130.

Haensch, Günther y Carlos OMEÑaca (2004): Los diccionarios del español en el siglo XXI, Salamanca, Ediciones Universidad de Salamanca.

López del Castillo, Lluís (2002): Diccionari de formació de paraules, Barcelona, Edicions 62.

Lorenzo, Emilio (1996): Anglicismos hispánicos, Madrid, Gredos. 
Lorenzo García, Esther (2007): «Anglicismos en -ing: reflexiones sobre un fenómeno en alza », en Mar Campos, Montserrat Muriano y José Ignacio Pérez Pascual (eds.), El nuevo léxico, A Coruña, Universidade da Coruña, Servizo de Publicacións, Anexos de Revista de Lexicografía, 4, pp. 113-128.

Martínez de Sousa, José (1995): Diccionario de lexicografía práctica, Barcelona, VOX-Biblograf.

Moll, Francesc de B. (1991): Gramática histórica catalana, València, Universitat de València, 8.

NTLLE = Real ACAdemia Española: Nuevo tesoro lexicográfico de la lengua española. En línea: <http://ntlle.rae.es/ntlle/SrvltGUILoginNtlle> [junio 2019].

Paredes Duarte, M. Jesús (2007-2008): «El principio de economía lingüística », Pragmalingüistica, 15-16, pp. 166-178.

Penny, Ralph (2006): Gramática histórica del español, $2^{\text {a }}$ ed. actualizada, Barcelona, Ariel Lingüística.

Pharies, David (2002): Diccionario etimológico de los sufijos españoles, Madrid, Gredos.

Prat SABATER, Marta (2016): «Proceso de integración de las incorporaciones léxicas en español: aspectos teóricos y presencia lexicográfica », Anuario de Letras (Lingüistica y Filología), IV (sem. 2), pp. 245-295. En línea: <http:// dx.doi.org/10.19130/iifl.adel.4.2.2016.1398>.

Prat Sabater, Marta y Sonia Sierra Infante (2011): «Los neologismos en la sociedad de la información: análisis de su presencia y ausencia en las fuentes lexicográficas escolares», Education in the Knowledge Society, 12 (3), pp. 141-164.

PRATT, Chris (1980): El anglicismo en el español peninsular contemporáneo, Madrid, Gredos.

Real Academia Española y Asociación de Academias de la Lengua Española (2010): Ortografía de la lengua española, Madrid, Espasa Libros.

Reverte, Javier (2010): «Este verano último se puso de moda un "ing” salvaje. Con guasa macabra, los medios lo bautizaron "balconing” », Viajar: la primera revista española de viajes, 379, p. 44.

Romero Lesmes, M. ${ }^{a}$ Dolores (2015): «Las construcciones con el verbo hacer y un anglicismo nominal en -ing», CHIMERA: Romance Corpora and Linguistic Studies, 2, pp. 35-48.

SANTAmaría PÉrez, Isabel (2006): «El léxico de la ciencia y de la técnica», Biblioteca de recursos electrónicos de humanidades, pp. 1-26. En línea: <https:// rua.ua.es/dspace/bitstream/10045/12767/8/L\%C3\%A9xico_de_la_ciencia_y_de_la_t\%C3\%A9cnica.pdf> [mayo 2019]. 
SECO, Manuel (2007): «El relevo de las palabras», en Mar Campos, Montserrat Muriano y José Ignacio Pérez Pascual (eds.), El nuevo léxico, A Coruña, Universidade da Coruña, Servizo de Publicacións, Anexos de Revista de Lexicografia, 4, pp. 9-25.

Valueiro Romero, M. ${ }^{a}$ Montserrat (2012): «Ciberlenguaje juvenil en las redes sociales», en Congreso Iberoamericano de las Lenguas en la Educación y en la Cultura / IV Congreso Leer.es, pp. 1-8. En línea: <https://www.academia. edu/9660839> [mayo 2019].

Vila Rubio, Neus y Lirian Ciro (2016): «Evolución de acepciones de términos informáticos en el DRAE (1970-2001): del léxico general al de especialidad... ¿y viceversa?», en Cecilio Garriga y José Ignacio Pérez Pascual (eds.), Lengua de la ciencia e historiografía, A Coruña, Universidade da Coruña, Servizo de Publicacións, Anexos de Revista de Lexicografía, 35, pp. 321-341.

Zamora Vicente, Alonso (1986): «Mitin, dar el mitin», Filología, 21 (2), 117 123.

Fecha de recepción: 31 de julio de 2019 Fecha de aceptación: 28 de octubre de 2019 


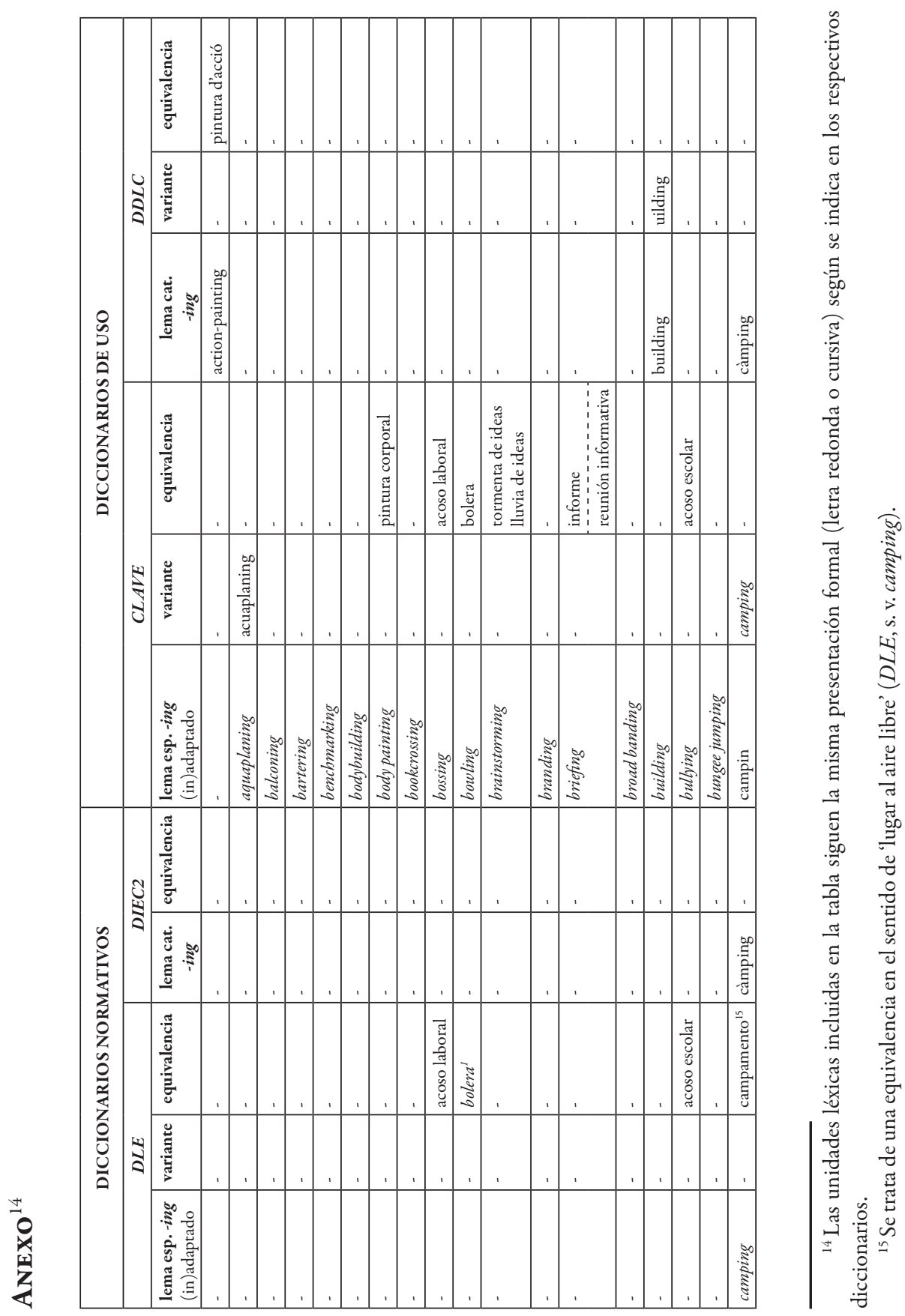



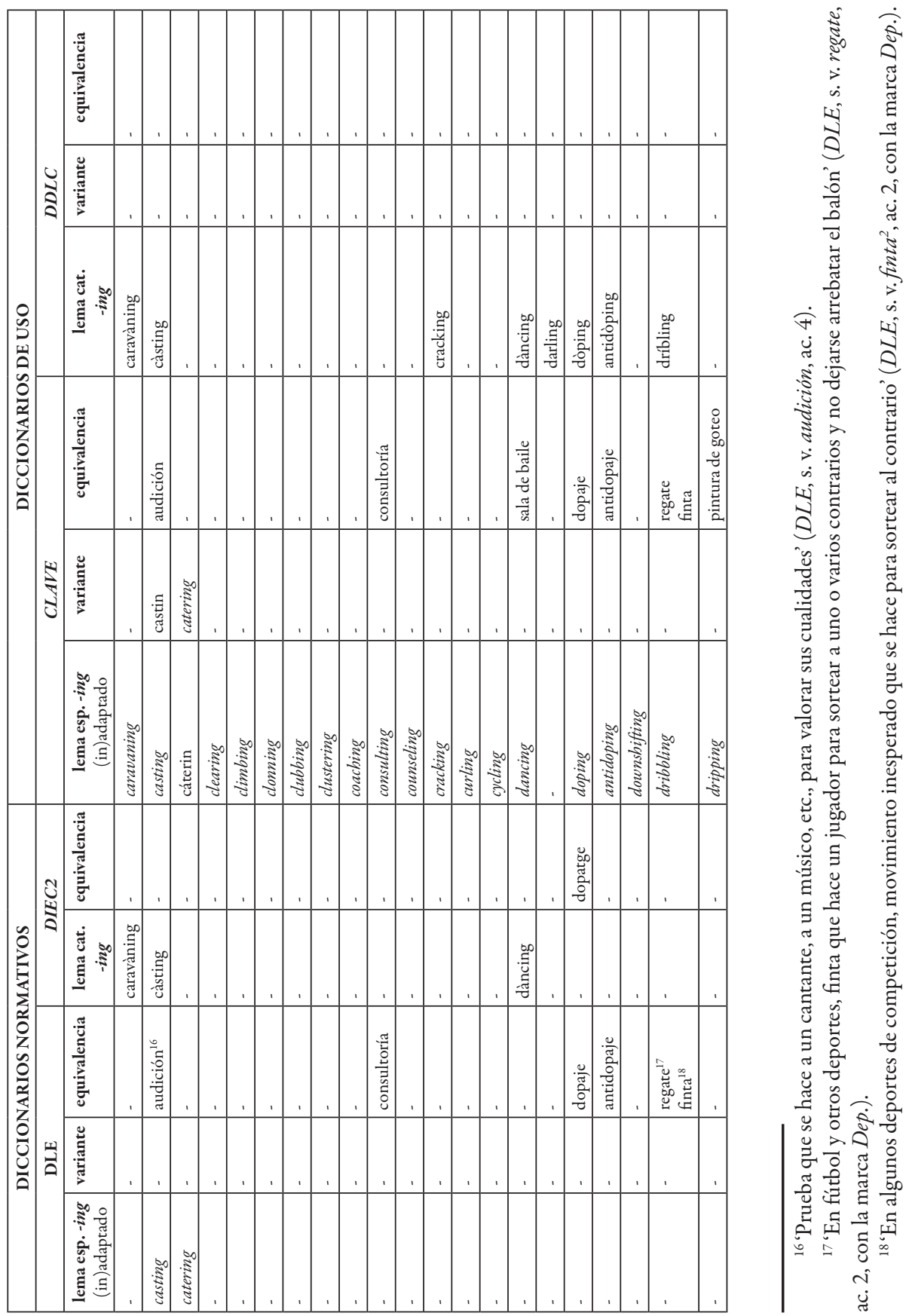


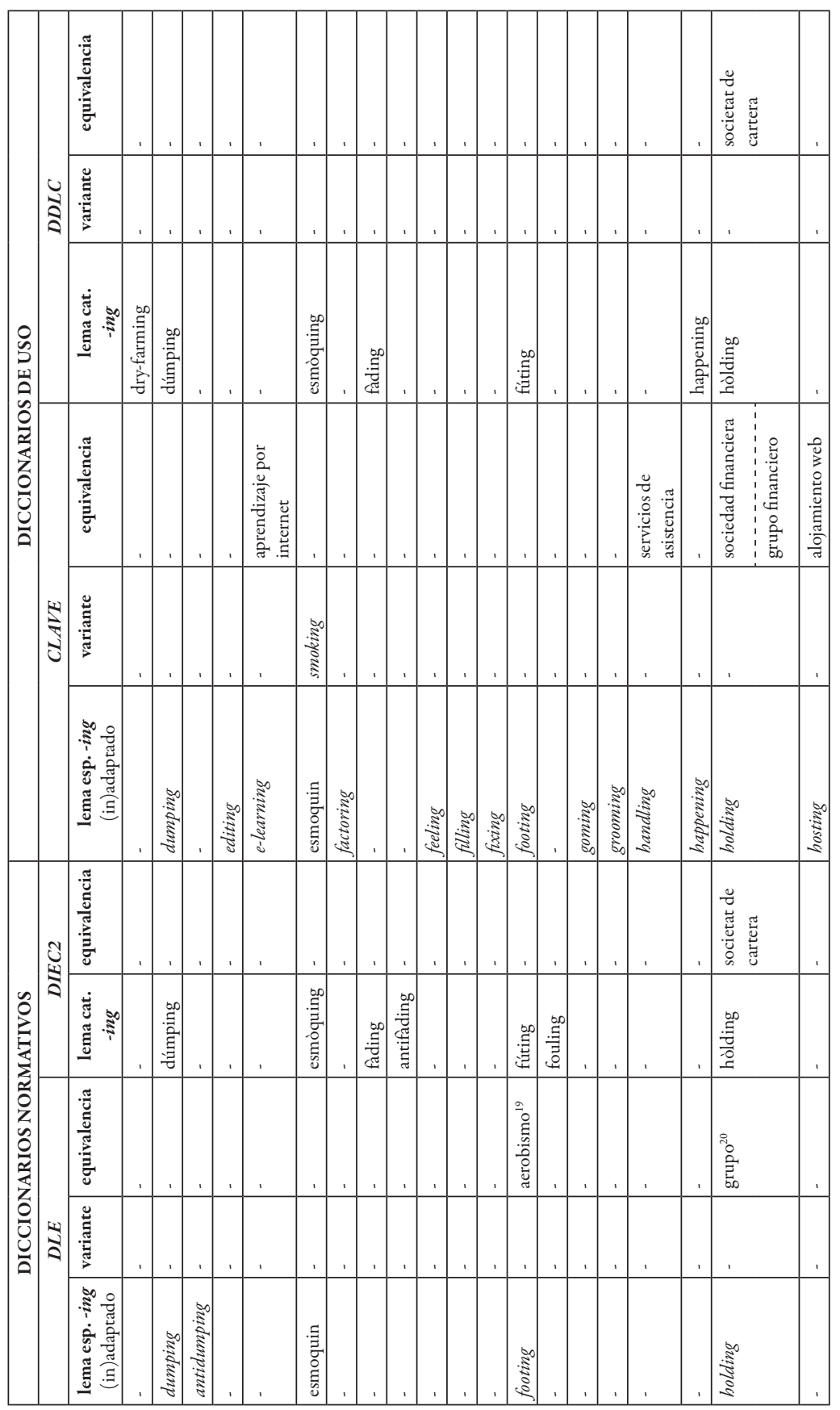

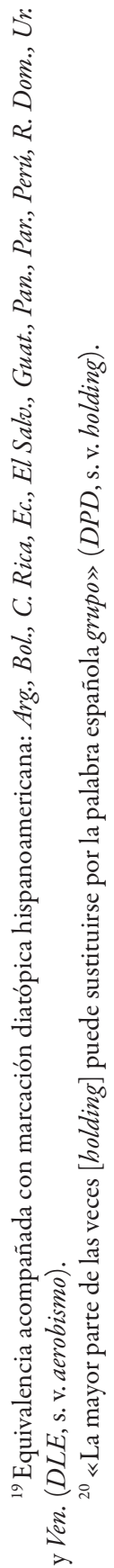




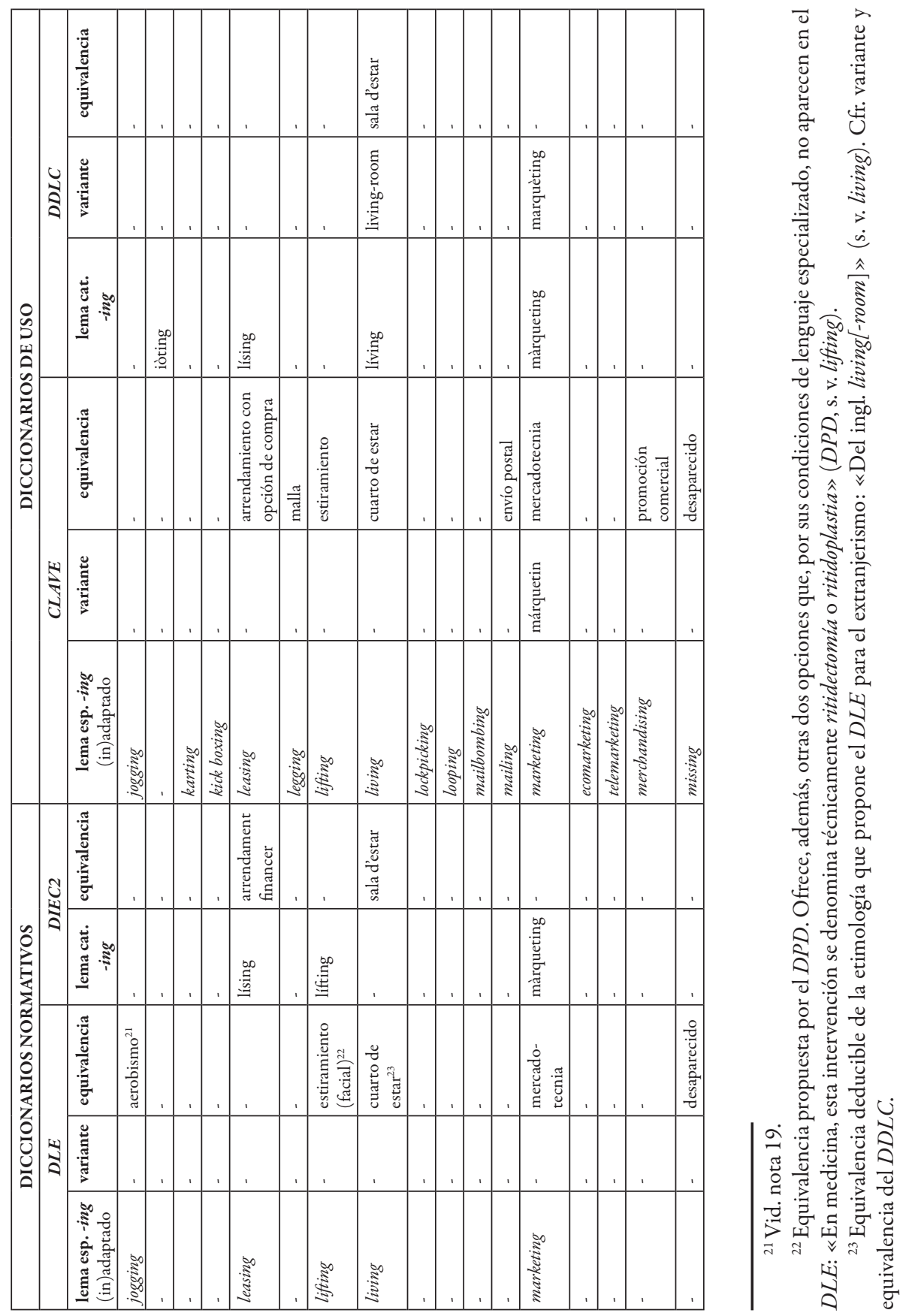




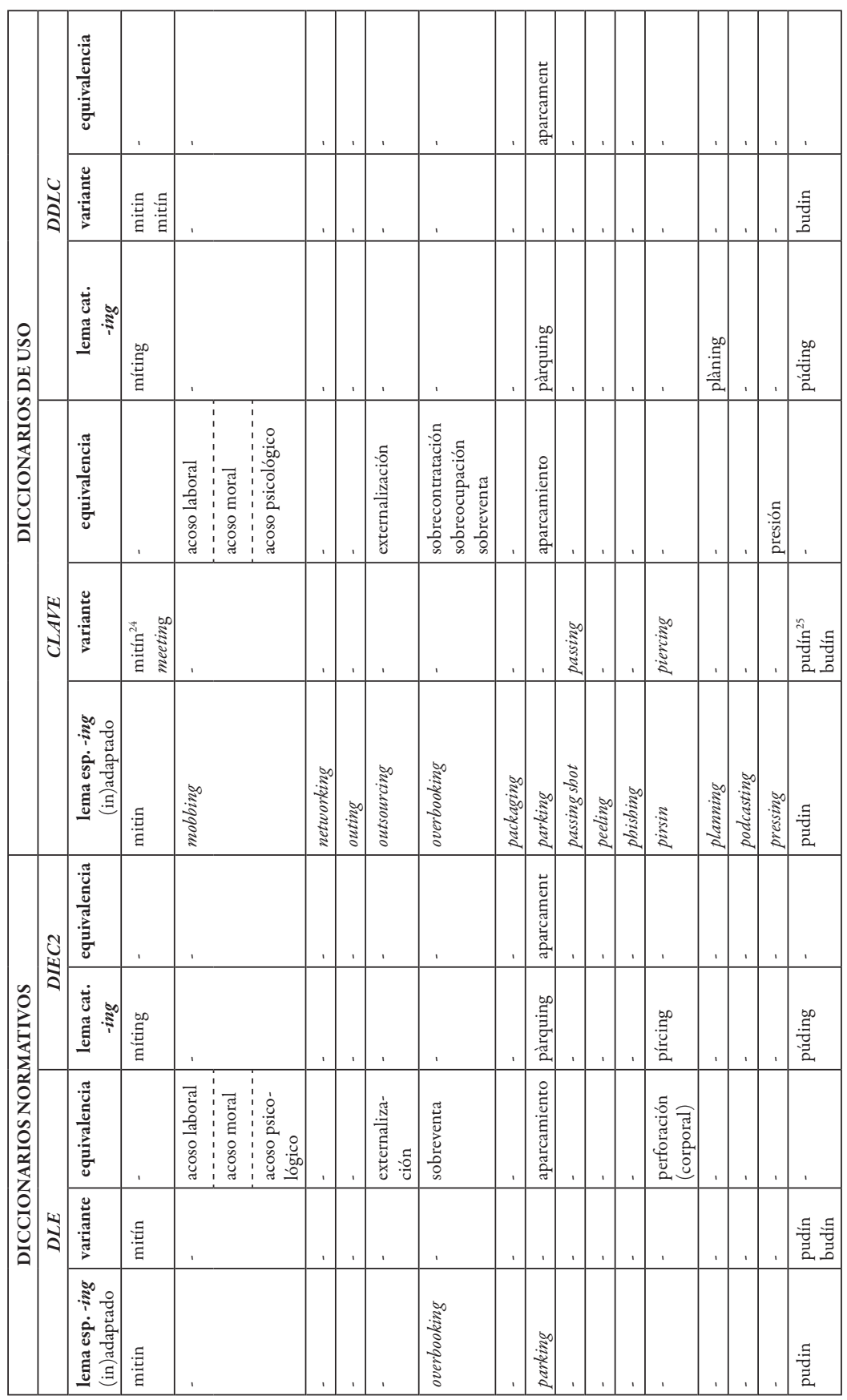

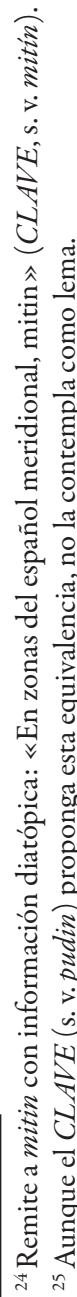




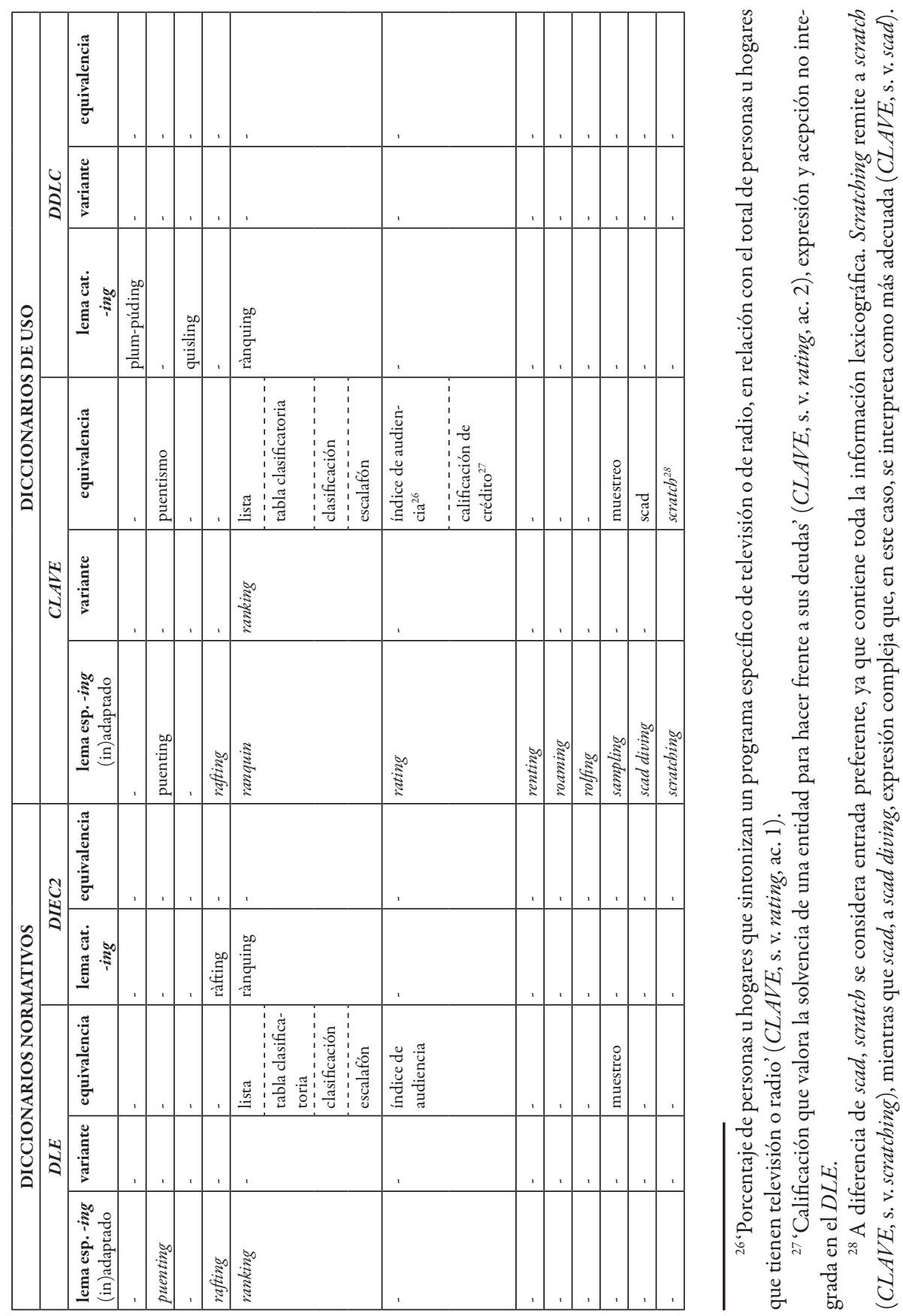




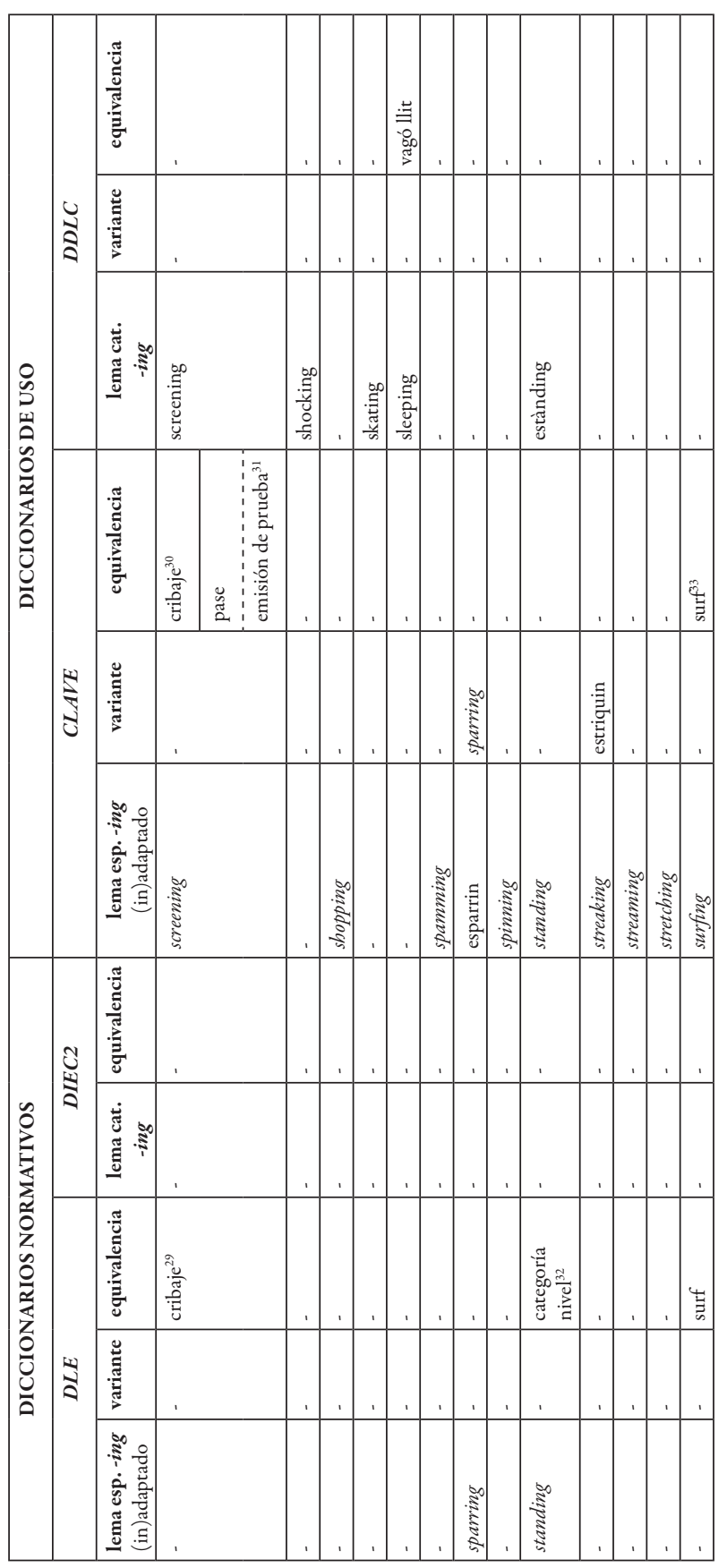

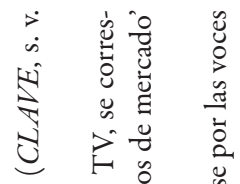

品

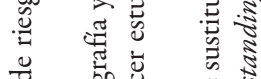

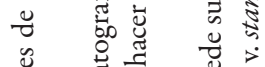

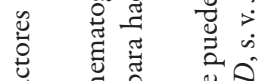

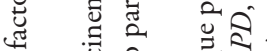

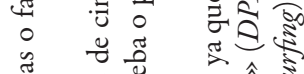

䒕

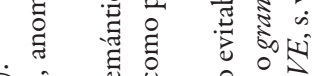

官论 की

䒕苞

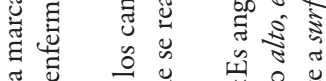

플

ठ․

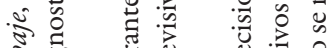

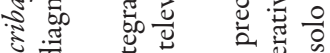

$\rightarrow$ 苛

मे

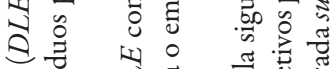

○渮

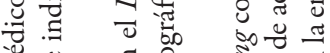

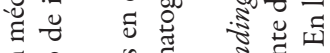

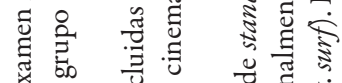

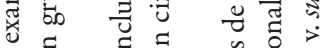

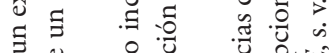

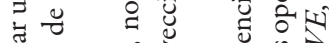

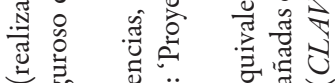

¿

है चี

ป

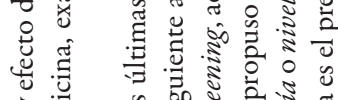

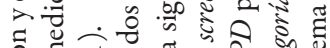

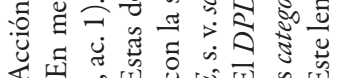

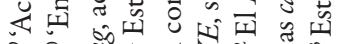

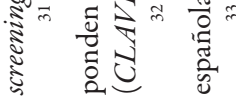



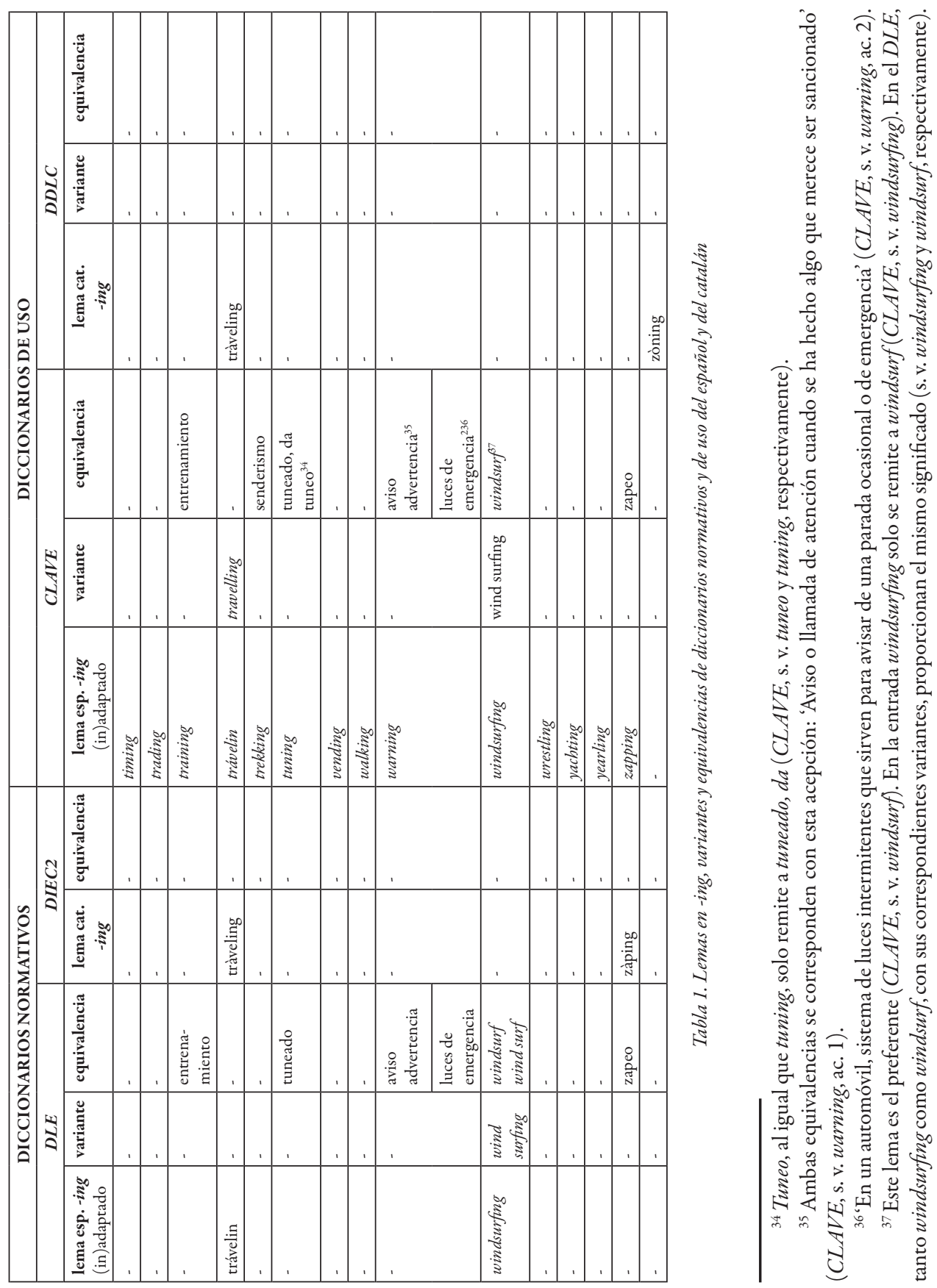